\title{
Telomere Maintenance in Organisms without Telomerase
}

\author{
James M. Mason ${ }^{1}$, Hemakumar M. Reddy ${ }^{1}$ and \\ Radmila Capkova Frydrychova ${ }^{2}$ \\ ${ }^{1}$ National Institute of Environmental Health Sciences \\ 2Institute of Entomology \\ 1 United States \\ ${ }^{2}$ Czech Republic
}

\section{Introduction}

Telomeres serve two vital functions to eukaryotes. They act as a protective chromosome cap to distinguish natural chromosome ends from double stranded DNA breaks and to avoid inappropriate fusions of telomeric sequences, and they maintain chromosome length by adding DNA to the ends of chromosomes. Telomeres thus balance the loss of terminal DNA due to the inability of the replication machinery to completely replicate linear DNA molecules (Olovnikov, 1973; Watson, 1972). In many cases the newly replicated chromosome ends are resected to allow for the formation of a t-loop that helps to hide the tip (Griffith et al., 1999; Wellinger et al., 1996). Most eukaryotes elongate chromosome ends with a special reverse transcriptase, telomerase, that carries a specific RNA template with telomeric sequence (Greider, 1996). The telomerase enzyme repeatedly adds copies of the short telomeric DNA sequence to the chromosome end. While there is strict conservation of telomeric sequence repeat in most species, the repeat unit has changed over evolutionary time. Holotrichous ciliates, e. g. Tetrahymena, use the sequence (TTGGGG) (Blackburn \& Gall, 1978), while hypotrichous ciliates, e. g. Oxytricha, use (TTTTGGGG)n (Klobutcher et al., 1981; Oka et al., 1980). The primary telomeric sequence in plants is (TTTAGGG) (Richards \& Ausubel, 1988; Zellinger \& Riha, 2007), although the alga Chlamydomonas uses (TTTTAGGG) $)_{n}$. In the yeasts the telomeric sequence has the same general motif, but is not as tightly controlled. Saccharomyces for example uses $\left(\mathrm{TG}_{1-3}\right)_{\mathrm{n}}$ (Shampay et al., 1984; Wang \& Zakian, 1990), while Schizosaccharomyces has (TTACAG $\left.{ }_{1-8}\right)_{n}$ (Matsumoto et al., 1987). The sequence found at the telomeres of most metazoans is (TTAGGG) $($ Meyne et al., 1989; Traut et al., 2007), although arthropods use (TTAGG)n (Okazaki et al., 1993).

Lack of the predominant telomeric sequence in a species does not, however, signify that telomerase-generated terminal sequences are missing. For example, the metazoan-type telomeric sequence is found in place of the plant sequence in Aloe species (Weiss \& Scherthan, 2002). In order to establish that a telomerase- independent, chromosome maintenance system exists it is also necessary to show a lack of a telomerase gene and telomerase activity, and to identify the nature of the DNA sequence at the chromosome termini. Establishing the negative is always difficult, and confirming that a specific sequence is at, not merely near, the chromosome tip is not trivial. Conversely, the presence of a 
canonical telomeric sequence does not necessarily indicate telomerase as a telomere maintenance mechanism. Some species of Calcarea (sponges), Cnidaria (sea anemones and jellyfish) and Placozoa, which keep the metazoan telomeric sequence, display little or no telomerase activity (Traut et al., 2007).

Although telomerase may have been the mechanism of telomere maintenance of the last common eukaryotic ancestor, it is not the only mechanism used to maintain chromosome length. Telomerase has been lost a few times in the evolution of plants and animals. During insect evolution, for example, telomerase has been lost at least six times. Here, we discuss telomere maintenance mechanisms that replaced telomerase in telomere length maintenance. In most cases the nature of the chromosome ends in organisms lacking telomerase is not known. In some species the telomerase-generated short telomeric repeat arrays have been replaced by tandem arrays of DNA sequences that look much like heterochromatin and can be elongated by copying information from one chromosome end to another, i. e. gene conversion. A completely different mechanism has been found in Drosophila, where tandem arrays of nonlong terminal repeat (LTR) retrotransposons are found. Newly synthesized copies of these retrotransposons target chromosome ends and can even transpose to unique sequence chromosome ends. Similar telomere-specific retrotransposons have been found in Drosophila species that diverged as long as 40 million years ago, suggesting that this mechanism is reasonably stable. Three families of retrotransposons are found at Drosophila telomeres; these elements may cooperate with each other during transposition to maintain all three in the Drosophila genome. Mutations are known that either increase or decrease the rate of addition to the chromosome ends, leading to longer or shorter terminal retrotransposon array lengths. While these mutations have not been well characterized, they suggest that telomere maintenance by retrotransposition is genetically regulated by the host.

\section{Plants without telomerase}

The plant telomeric sequence (TTTAGGG) $)_{\mathrm{n}}$ appears to be highly conserved in all phyla of the plant kingdom (Fuchs et al., 1995; Fuchs \& Schubert, 1996; Richards \& Ausubel, 1988). Nevertheless, in the order Asparagales the plant telomeric motif has been replaced with (TTAGGG) $)_{\mathrm{n}}$ but is still maintained by telomerase (Fajkus et al., 2005). In addition, three genera within the family Solanaceae appear to have lost both the canonical telomeric DNA motif as well as telomerase, which is required to maintain this motif.

\subsection{The nightshade family}

In the family Solanaceae the canonical plant telomeric repeat is replaced by a less conventional telomeric sequence that may be associated with a different compensation pathway. Detailed analysis of Solanaceae species revealed that although plant telomeric sequence is present in tobacco, tomato and other representatives of this family, the telomeric motif and telomerase activity are missing in the three closely related genera of Cestrum, Vestia and Sessea. The actual telomeric sequence and compensation mechanism in this group of plants, however, remain unknown (Fajkus et al., 1995; Peska et al., 2008; Sykorova et al., 2003; Watson \& Riha, 2010).

\subsection{The onion family}

Chromosome termini of the onion, Allium cepa, and other Alliaceae species represent another known case of unusual telomeres lacking telomerase in plants. Telomeres of $A$. сеpa 
consist of two tandemly organized repeats - a 375-bp satellite sequence and rDNA repeats (Barnes et al., 1985; Pich et al., 1996; Pich \& Schubert, 1998). Besides this, the telomeres in A. серa are enriched with En/Spm transposable element-like sequence and Ty1-copia-like retrotransposons. The Ty1-copia retroelements have been reported not only at telomeres of A. cepa but dispersed throughout its genome (Pearce et al., 1996; Pich \& Schubert, 1998). Based on these findings it has been proposed that the telomeres of Alliaceae species are maintained through transposition of the mobile elements or through homologous recombination between the satellite sequences (Pich et al., 1996; Pich \& Schubert, 1998).

\section{Animals without telomerase}

In the case of animals, the lack of a telomerase system has been reported in a few insect species. The (TTAGG) $n$ sequence has been detected in most tested insect orders and is considered as the ancestral telomeric motif not only for insects but also for all arthropods (Vitkova et al., 2005). In some groups of arthropods, such as damselflies or spiders this telomeric motif was lost (Frydrychova et al., 2004; Vitkova et al., 2005), however in most cases it remains unknown if the sequence was replaced by another similar motif or a different type of sequence associated with a telomerase-independent elongation mechanism (Figure 1).

\subsection{The silkworm}

A highly interesting case of telomeres was revealed in another model organism, the silkworm, Bombyx mori (Lepidoptera). The telomeres of the silkworm consist of the insect telomeric repeats but harbor many types of non-LTR retrotransposons, designated TRAS and SART families (Fujiwara et al., 2005; Kubo et al., 2001; Okazaki et al., 1995). TRAS and $S A R T$ are abundantly transcribed and actively transpose into TTAGG telomeric repeats in a highly sequence-specific manner. The silkworm genome contains a telomerase gene, but the telomerase itself displays little or no enzymatic activity. It is believed that compensation of telomeric loss in B. mori occurs almost exclusively by transposition of TRAS and SART elements to the chromosome ends (Fujiwara et al., 2005; Tatsuke et al., 2009). Nevertheless, in contrast to Drosophila, in which the telomerase system was completely lost and replaced by telomeric retrotransposition (see below), B. mori may be in transition from one telomere elongation pathway to another.

\subsection{Lower diptera}

Telomerase has not been found in any dipteran species (Figure 1). As fossils for this order date to the middle Triassic period, it is possible that telomerase may have been lost as much as 225 million years ago. Nevertheless, Diptera as a group are very successful, accounting for some $10 \%$ of known animal species. Thus, loss of telomerase does not seem to have been a major impediment to survival. Replacement of short telomerase-generated repeats with long satellite sequences is reported in lower dipteran species. Chromosome tips of nonbiting midges (genus Chironomus) consist of large, 50-200 kb, blocks of complex, tandemly repeated sequences that are classified into subfamilies based on sequence similarities. Different telomeres display different sets of subfamilies, and the distribution of subfamilies differs between different individuals in a stock. The variation of the satellite sequences supports the proposal that telomeres in Chironomus are elongated by a homologous 


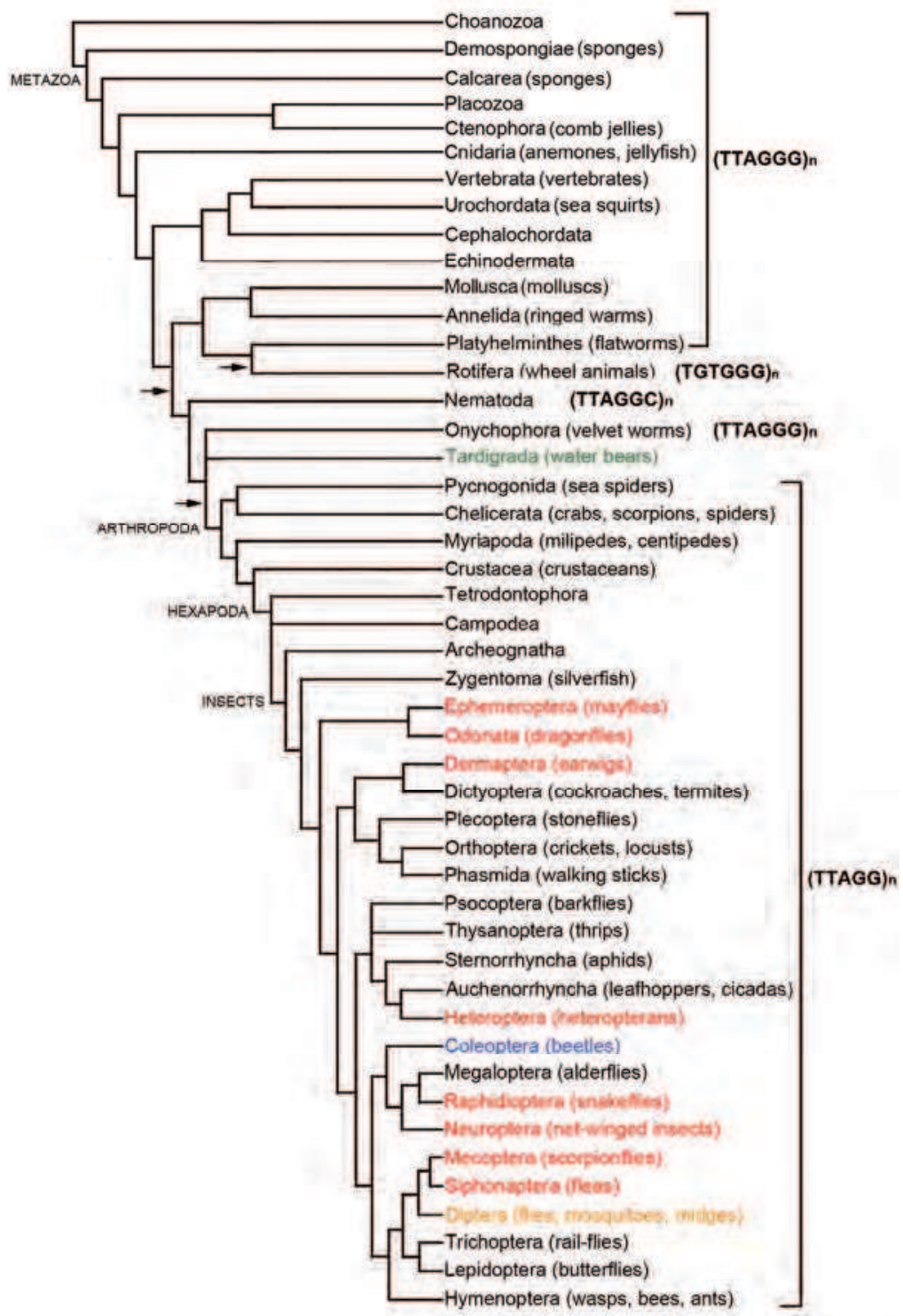

Fig. 1. Distribution of telomere repeat motifs in Metazoa. (TTAGGG) ${ }_{\mathrm{n}}$ is the ancestral telomeric sequence of Metazoa and its sister group, Choanozoa. The ancestral motif was replaced with $($ TTAGG) $\mathrm{n}$ and (TTAGGC) $\mathrm{n}$ in Arthropoda and Nematoda, respectively. Tardigrada (green) do not display either of these motifs. Insect orders in red do not exhibit the arthropod sequence. Coleoptera (blue) is heterogeneous for the arthropod motif. With a few exceptions among Diptera, Tardigrada and the insect orders in color have unknown telomeric sequences. Arrows mark the replacement of the metazoan motif with other motifs, as shown. The cladogram is based on Frydrychova et al., 2004; Vitkova et al., 2005; Traut et al., 2007. 
recombination mechanism involving these long blocks of complex repeat units (Biessmann \& Mason, 1997; Cohn \& Edstrom, 1992; Cohn \& Edström, 1992; Nielsen \& Edstrom, 1993). A situation has been observed in Anopheles gambiae with a plasmid insertion into the complex satellite telomeric sequences at the tip of chromosome 2L. The plasmid sequence was used as a marker to follow the specific telomere, which was found to engage in frequent recombination events to extend the array length (Biessmann et al., 1998; Roth et al., 1997). Recently, a similar case was reported in Rhynchosciara americana (Madalena et al., 2010). Tandem arrays of short repeats, 16 and $22 \mathrm{bp}$ in length, were found to extend to chromosome ends. Although telomere elongation could not be assayed in this case, it seems likely that the mechanism is similar to that seen in other dipterans. In many respects, these complex arrays resemble subtelomeric sequences (Pryde et al., 1997).

\subsection{Drosophila}

Most of our information on the structure and maintenance of telomeres in Drosophila is based on $D$. melanogaster, although some recent studies have been performed on other species, especially D. virilis. As in other dipterans, Drosophila telomeres do not posses a canonical telomeric sequence and are not maintained by a telomerase-dependent system. Instead, chromosome ends in Drosophila carry an array of retrotransposons. This unusual telomere structure is common among all drosophilids that have been studied (Casacuberta \& Pardue, 2002, 2005), although species within this genus may have diverged as much as 40 million years ago (Russo et al., 1995).

\subsubsection{Drosophila melanogaster}

Three distinct telomeric regions have been identified in Drosophila (Andreyeva et al., 2005; Biessmann et al., 2005). At the extreme terminus is a proteinaceous chromosome cap that covers approximately $4 \mathrm{~kb}$ of terminal DNA sequence (Melnikova \& Georgiev, 2005) and identifies the end as distinct from a chromosome break. The telomere-specific components of the cap in Drosophila are collectively termed 'terminin' by analogy to the shelterin protein complex at mammalian telomeres (Raffa et al., 2009). The terminin proteins differ from the shelterin proteins, in part because the TRF1 and TRF2 components of shelterin bind specifically to the canonical telomeric repeat, while the formation of the telomere cap in Drosophila is sequence independent, and in part because many of the terminin proteins are among the fastest evolving proteins in Drosophila (Gao et al., 2010; Raffa et al., 2010; Schmid \& Tautz, 1997). There is no direct evidence that the cap in Drosophila plays a role in maintaining chromosome length. Most chromosome ends in Drosophila carry a tandem array of telomere-specific non-LTR retrotransposons (Mason \& Biessmann, 1995; Pardue \& DeBaryshe, 2003), although the length of this array can vary considerably. Located between the terminal retrotransposons and the unique sequence DNA of euchromatin is another repeat array. This array is often referred to as telomere associated sequences (TAS) or the subtelomere region (Karpen \& Spradling, 1992; Walter et al., 1995). As in other eukaryotes TAS sequences in Drosophila include irregular arrays of relatively long repeat units that can vary from one chromosome end to another within the same organism (Pryde et al., 1997).

\subsubsection{Telomeric retrotransposons}

Studies on D. melanogaster revealed three telomere-specific retrotransposable elements, $\mathrm{HeT}$ A, TART and TAHRE (collectively abbreviated HTT) present in multiple copies on each 
chromosome end. These retrotransposons are in the same family of elements as mammalian LINEs. Although the D. melanogaster genome has some 60 families of known retrotransposable elements, only these three are found at chromosome ends. Further, these three elements are present only in the telomere arrays. HTT elements are not found in euchromatic regions, although tandem arrays of short segments of the 3 ' noncoding region of $\mathrm{HeT}-\mathrm{A}$ have been found in centric heterochromatin, especially in the $Y$ chromosome (Abad et al., 2004a; Agudo et al., 1999; Berloco et al., 2005).

As a group the HTT elements have characteristics that distinguish them from other retrotransposons (Figure 2A). HeT-A is about $6 \mathrm{~kb}$ in length, has only a single open reading frame (ORF), encoding a Gag-like nucleic acid binding protein, but lacks an ORF for a

A

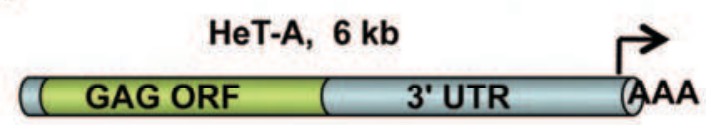

TAHRE, $10 \mathrm{~kb}$

GAG ORF ( RT ORF ( 3' UTR

AAA

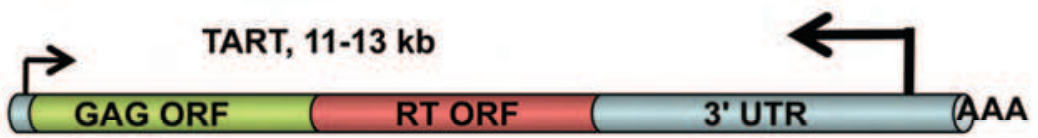

B

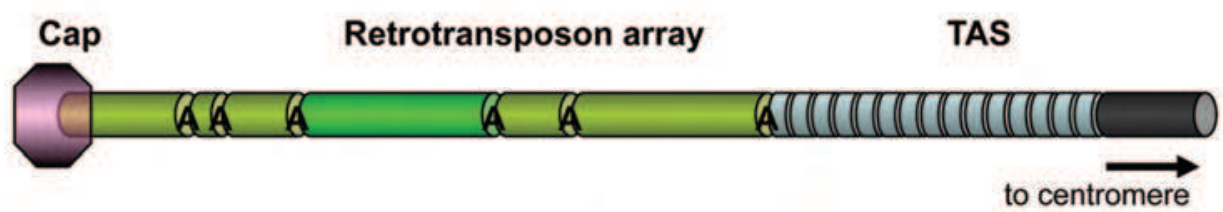

Fig. 2. Structure of Drosophila telomeres. (A) There are three families of telomeric non-LTR retrotransposons. The GAG open reading frame encodes a nucleic acid binding protein that helps to target chromosome ends. The RT open reading frame encodes a reverse transcriptase needed to copy the RNA intermediate onto the chromosome end. HeT-A does not carry a reverse transcriptase gene. All three elements carry relatively short $5^{\prime}$ UTRs and very long 3' UTRs. Promoters are indicated by bent arrows. The 3' oligo(A) tail used to attach to chromosome ends is indicated by AAA. TART has a strong antisense promoter. (B) The Drosophila terminal array is composed of a tandem mixed array of variably 5 truncated transposons. At the distal end the chromosome carries a protein complex that binds to the end independently of DNA sequence and stabilizes the terminus. The "A" at each junction indicates the 3 ' oligo(A) tail. Proximal to the retrotransposons is a complex subterminal, telomere associated sequence (TAS) followed by unique sequence chromosomal DNA. Adapted from Capkova Frydrychova et al., 2008). 
reverse transcriptase. HeT-A also has a $2.4 \mathrm{~kb} 3^{\prime}$ untranslated region (UTR), which includes two to five imprecise $80 \mathrm{bp}$ tandem repeats that may help establish chromatin structure. This region has a strong G-rich strand bias, which resembles the strand bias found in canonical telomeric motifs (Abad \& Villasante, 1999; Biessmann et al., 1992b; Danilevskaya et al., 1998a), suggesting selection for their presence. Despite the fact that the sequence of the 3' UTR of D. yakuba, a sister species of D. melanogaster, has diverged by about $50 \%$, these repeat features have been conserved (Danilevskaya et al., 1998b). The TART element is about $10 \mathrm{~kb}$ in length with two ORFs, which encode a Gag protein and a Pol protein with a reverse transcriptase domain. TART also carries a pair of perfect non-terminal repeats that may be important for its replication (Sheen \& Levis, 1994; George et al., 2010). TAHRE is about 11-13 $\mathrm{kb}$ in length and has extensive sequence similarity to HeT-A along its entire length, except that it carries a second ORF for a reverse transcriptase (Abad et al., 2004b; Shpiz et al., 2007). As they all carry unusually long 3' UTRs of about 2-3 kb, the HTT retrotransposons are exceptions to the pattern that transposable elements usually have very little sequence that does not code for polypeptides involved in their own transposition (Abad et al., 2004b; Biessmann et al., 1992b; Sheen \& Levis, 1994). It seems likely that this non-coding DNA is related to their role at the telomere (Villasante et al., 2007).

\subsubsection{The terminal retrotransposon array}

The three retrotransposons present in Drosophila telomeres are arranged in head-to-tail arrays of mixed complete and 5'-truncated elements with their $3^{\prime}$ oligo-A tails oriented toward the centromere (Figure 2B). HeT-A is the most abundant of the three families, accounting for $80-90 \%$ of the telomeric array. TART elements occupy about $10 \%$, while TAHRE elements occupy only $1-2 \%$ of the telomeric array. The 5 ' ends of many of these elements are truncated to varying extents, as might be expected from terminal erosion due to the end replication problem or incomplete reverse transcription (Mason \& Biessmann, 1995). In one stock the HTT array length varied from about 20 to $150 \mathrm{~kb}$ for individual chromosome ends (Abad et al., 2004a). The length and composition of the telomeric retrotransposon arrays can also vary significantly between chromosomes and among fly stocks (Walter et al., 1995). In some mutants the terminal array may be several fold longer than found in standard laboratory strains (Melnikova \& Georgiev, 2002; Savitsky et al., 2002; Siriaco et al., 2002). Conversely, not all chromosome ends in Drosophila have terminal retrotransposon arrays. Broken chromosomes with ends far from the original telomere have been found in a number of different circumstances (Capkova Frydrychova et al., 2008). It is important to note that these broken chromosome ends lack both the retrotransposon array and TAS but do not induce cell cycle arrest and are not subject to DNA repair or telomere fusions. These broken chromosome ends can be maintained in vivo for hundreds of generations without gaining new HTT sequences (Biessmann et al., 1990a; Cenci et al., 2003; Fanti et al., 1998). Thus, these broken chromosome ends have been 'healed' in the sense that McClintock (1941) described newly stabilized broken chromosome ends, and they are associated with a protein complex that includes a number of terminin proteins (Cenci et al., 2005; Ciapponi \& Cenci, 2008). This suggests that chromosome caps in Drosophila are epigenetic and form independently of telomeric DNA sequence (Biessmann \& Mason, 1988, 2003). These capped broken ends may eventually acquire retrotransposons by what appears to be a stochastic process (Biessmann et al., 1992a; Mikhailovsky et al., 1999).

As expected from the end replication problem, the broken chromosome ends recede. Erosion at these terminally deficient chromosomes was estimated at a constant rate of about $75 \mathrm{bp}$ 
per sexual generation (Biessmann \& Mason, 1988; Levis, 1989; Mikhailovsky et al., 1999). Considering the number of germline cell divisions, the rate of terminal erosion was estimated at 2-3 bp per chromosome end per cell cycle (Biessmann \& Mason, 1988). This is formally equivalent to the degradation of an 8-12 nt RNA primer from the end of the lagging strand after each round of replication leaving a short $3^{\prime}$ overhang (Biessmann et al., 1990a). In mammals telomere erosion is faster, in large part because chromosome ends are resected to produce relatively long 3' overhangs necessary for t-loop formation (Griffith et al., 1999; Wellinger et al., 1996). The slow rate of loss in Drosophila suggests that resection of the chromosome ends after replication is not extensive, and that t-loops are not required for telomere protection. It is possible that chromosome ends with telomeric retrotransposons behave differently from healed broken ends, but to date the evidence is lacking.

\subsubsection{Transposition to elongate telomeres}

To counter terminal erosion and maintain their length, telomeres must be elongated. The broken chromosome ends provide an entrée to study telomere elongation. Southern blots to monitor terminal fragment length at a broken chromosome end identified the addition of new sequence onto the terminal fragment at a frequency of about $1 \%$ per generation, with an average length for the added fragment of $6 \mathrm{~kb}$ (Biessmann et al., 1992a; Biessmann et al., $1990 \mathrm{~b})$. This averages out to an addition of $60 \mathrm{bp}$ per generation, just enough to balance terminal erosion. It is important to note that the frequency of addition onto chromosome ends may be sensitive to different factors, including genetic background and possibly external conditions. Using genetic assays, two groups have identified stocks with much different frequencies of addition, possibly by as much as two orders of magnitude in either direction (Golubovsky et al., 2001; Savitsky et al., 2002; Savitsky et al., 2006). The new additions onto the receding chromosome ends were identified as HeT-A and TART elements, the same retrotransposons as found at natural telomeres. These elements were attached to the broken end by an oligo(A) tail, as would be expected from retrotransposition (Figure 3). Further, when broken chromosome ends that had gained a HeT-A element were used as a target they too acquired new HeT-A elements by transposition (Biessmann et al., 1992a). Thus, retrotransposition through target primed reverse transcription may be a mechanism for extending natural chromosome ends as well as broken ends.

\subsection{The transcription step}

The first step in the process of retrotransposition is transcription of the transposable element (Figure 3). All three telomeric elements have unusual transcription patterns. TART has active promoters at both the $5^{\prime}$ and $3^{\prime}$ ends that initiate in both the sense and antisense directions, although the major product seems to be a nearly full length antisense RNA (Danilevskaya et al., 1999; Maxwell et al., 2006). TART has a single promoter in the 5' UTR that drives transcription of the transposition intermediate (Maxwell et al., 2006). HeT-A and TAHRE, on the other hand, do not have promoters at the $5^{\prime}$ end. Instead, they have a promoter in the $3^{\prime}$ end that drives transcription of the adjacent downstream element (Danilevskaya et al., 1997; Shpiz et al., 2007). This literally means that HeT-A promotes its neighbor. The placement of this promoter is important for the long-term integrity of the telomeric array, because a promoter in the standard 5 ' position would be subject to erosion due to the end replication problem and lost immediately after transposition. A 3 ' promoter resurrects the element downstream. HeT-A transcription is developmentally regulated and occurs only in diploid cells of ovaries, testes, imaginal discs, and embryos (Capkova Frydrychova et al., 2007). 


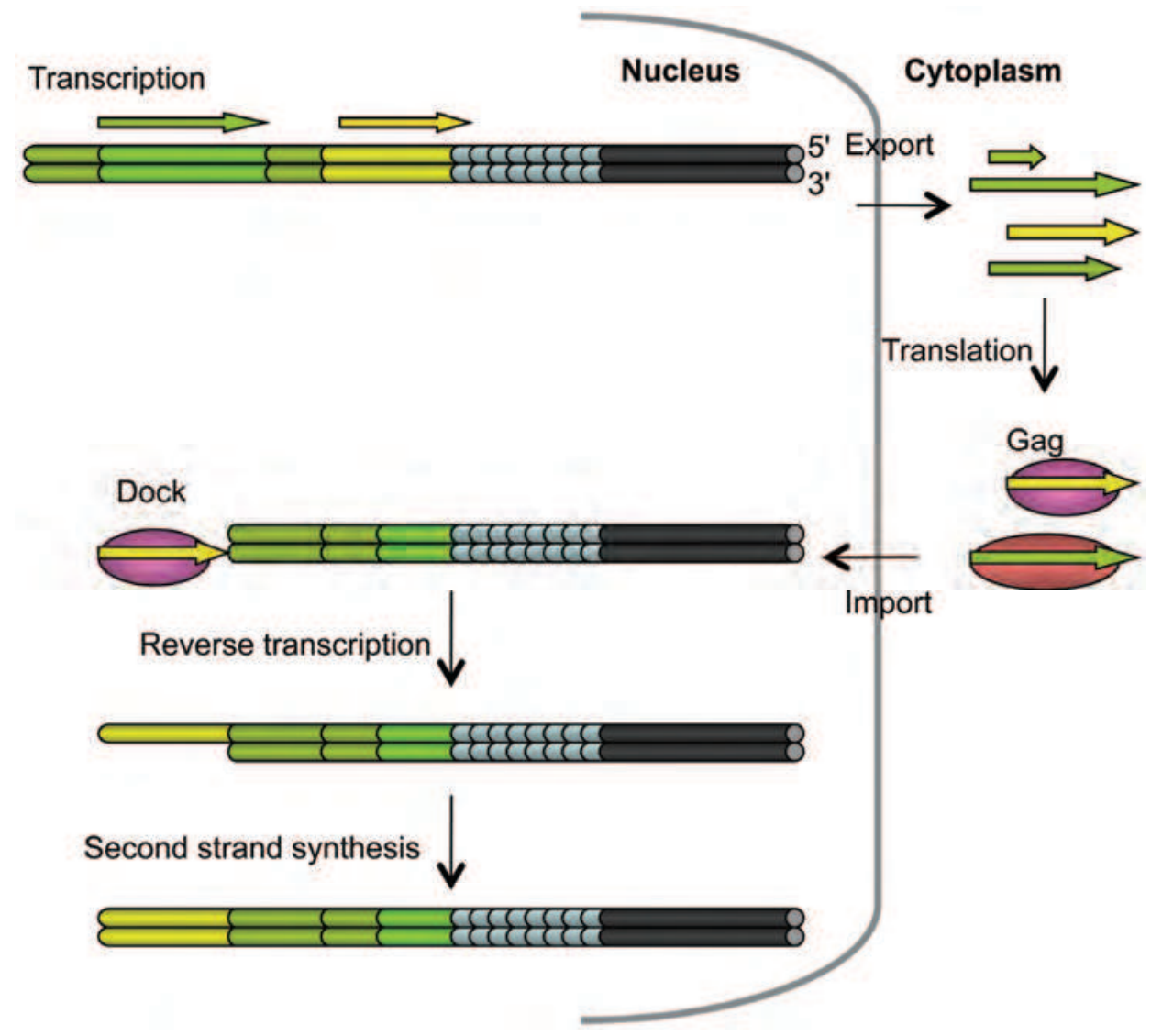

Fig. 3. Transposition as a mechanism for telomere elongation. The model proposes that transcripts (colored arrows) are generated from telomeric retrotransposons using promoter activity located in the $3^{\prime}$ UTR of an upstream HeT-A or TAHRE element. Transcripts leave the nucleus to serve as mRNA for translation of the encoded Gag protein and possibly reverse transcriptase (ovals). Gag proteins bind the RNA, facilitate re-entry into the nucleus and target the chromosome end. After docking to a telomere a reverse transcriptase uses the free 3' hydroxyl group at the chromosome end as primer to copy the RNA intermediate into the first DNA strand. Second strand synthesis completes the addition of a new retrotransposon. Sequence analyses of recently transposed HeT-A elements and several in native telomeric arrays suggest that there is a selection for the incorporation of elements with a functional Gag ORF.

One appealing mechanism for controlling the length of the terminal retrotransposon array is to regulate transcription of these elements. Two forms of this mechanism have been proposed, but both have problems. First, it was noted that transgenes inserted into subtelomere regions are repressed and variegate (Cryderman et al., 1999; Roseman et al., 1995). In addition, TAS arrays can silence in cis the activity of a neighboring transgene as well as a HeT-A element when they are distal (telomeric) of TAS (Boivin et al., 2003; 
Capkova Frydrychova et al., 2007; Kurenova et al., 1998), suggesting that TAS can control terminal retrotransposon array length by regulating transcription (Mason et al., 2003a). The TAS silencing effect, however, only extends a short distance into the terminal array and has little or no effect on overall HeT-A transcript levels (Biessmann et al., 2005; Capkova Frydrychova et al., 2007). Thus, silencing orchestrated by TAS arrays is not sufficiently strong to regulate transcription of the terminal retrotransposons. Second, it was noted that $H e T-A$ and TART transcript levels are under the control of an RNA interference pathway (Savitsky et al., 2006; Shpiz et al., 2009). Transposition frequency and terminal array length, however, did not increase with increasing retrotransposon transcript levels (Capkova Frydrychova et al., 2008). It thus appears that the transcript levels of these retrotransposons are not the limiting factor in their transposition.

\subsection{Telomere targeting}

After transcription the RNA is transported into the cytoplasm and translated. The HeT-A RNA produces only a Gag protein, which binds a transcript, enters the nucleus and attaches to chromosome ends. Evidence supports the hypothesis that the Gag protein binds preferentially to the transcript that encoded it, because while many HeT-A elements in the terminal array are 5 ' truncated or otherwise lack an ORF, newly transposed HeT-A elements have a complete Gag ORF (Biessmann et al., 1994). Unlike Gag proteins for closely related parasitic retrotransposons, the HeT-A and TART Gag proteins are transported efficiently into the nucleus (Rashkova et al., 2002b). Unlike other non-LTR elements telomere specific elements do not require nicked DNA, because they are reverse transcribed directly onto the end of the chromosome. The HeT-A Gag can associate with telomeres on its own. The TART Gag, however, can only be seen to associate with telomeres in the presence of expressed HeT-A Gag protein (Rashkova et al., 2002a). Similarly, transport of the TAHRE Gag into the nucleus is facilitated by HeT-A and TART Gag proteins (Fuller et al., 2010). This presents a possible explanation for the presence of HeT-A, TAHRE and TART transposons in all Drosophila stocks. HeT-A does not encode a reverse transcriptase, which is required for retrotransposition, but may use the one encoded by either the TART or TAHRE elements. TAHRE and TART, on the other hand, cannot target chromosome ends without the aid of the HeT-A Gag protein.

\subsection{Consequences of transposition on terminal array structure}

Given the constant erosion of chromosome ends and the stochastic addition of transposon sequences to the same ends, one might expect that the terminal retrotransposon array would be very dynamic, constantly changing in length and composition. We have found this to be true using a genetic assay for the number of transposons at a specific telomere (Golubovsky et al., 2001; Mason et al., 2003b). One consequence of this turnover is that the transposon elements at the terminus are younger than those nearer to TAS. Virtually complete terminal arrays have been identified in overlapping BAC clones (Abad et al., 2004a). The age differential can be seen in the distribution of transposable elements that do not specifically target the chromosome end. These transposons are found primarily in the older, proximal portion of the terminal array (Pardue \& DeBaryshe, 2008). Turnover in the younger, distal portion of array the removes evidence of these transposons. Newly transposed $P$ elements have also been found inserted into the terminal array with reasonable frequency (Biessmann et al., 2005). Although the exact positions of these $P$ elements in the terminal array could not be determined for most of the insertions, there is no evidence that any portion of the HTT array is refractory to insertion by non-telomere-specific elements. 
HeT-A transcription start sites reside 31 and 62 bp upstream of the oligo-A tail (Danilevskaya et al., 1997). Thus, newly transposed transposons are slightly longer than the same elements before transposition, because they carry a tag at the $5^{\prime}$ end identical to the $3^{\prime}$ end of the previous upstream element (Traverse et al., 2010). Surprisingly, some of the elements carry multiple tags, suggesting that they have transposed several times without being subjected to terminal erosion. The simplest explanation is that multiple transposition events occur in rapid succession, possibly more than one per generation. Evidence of this has been found in measurements of transposition rate (Biessmann et al., 1992a), in which it was found that many of the new sequence additions were $12 \mathrm{~kb}$ or longer, and the $3^{\prime}$ half of these long additions consisted of a $(6 \mathrm{~kb}) \mathrm{HeT}-\mathrm{A}$ element. As these long addition events were shown to be the result of transposition, they could have resulted from either rapid multiple transposition events or transcriptional read-through to produce an RNA intermediate encompassing more than one element. The latter, however, have been found to be relatively rare (Capkova Frydrychova et al., 2007) and don't explain the presence of tandem tags. Rapid multiple transposition events may be the natural consequence of terminal transposition. When one retrotransposon attaches to the chromosome end, the old protective telomere cap must jump to the new terminus 6-12 $\mathrm{kb}$ away. If the cap is unstable during this transition, more transposons may have access to the new terminus, allowing for more transposition events to occur in rapid succession.

The 5' and 3' UTRs of TART carry perfect non-terminal repeats. These repeated regions vary among TART families and among individuals within a family but are identical at both ends of individual elements (Sheen \& Levis, 1994). It has been proposed that the two repeated sequences evolve in concert by a mechanism of template switching during the reverse transcription step (George et al., 2010).

\subsubsection{Recombination to elongate telomeres}

Transposition is not the only mechanism for telomere elongation in Drosophila. Gene conversion allows genetic information to be transferred from one chromosome to another by homologous recombination (Figure 4). Georgiev and colleagues made use of broken chromosome ends with the yellow gene placed close to the terminus, such that the upstream controlling sequences were deleted, but the ORF was still present (Kahn et al., 2000; Mikhailovsky et al., 1999). Expression of the yellow gene was thus inactivated, but HeT-A transposition to the broken end could activate yellow expression via the promoter in its $3^{\prime}$ UTR, while recombination with a wild type chromosome can reintroduce the yellow promoter and enhancers to their position on the broken end. Genetic assays were used to identify changes in yellow expression, then the length and sequence of the upstream region were characterized. Approximately $20-30 \%$ of the yellow reactivation events were the result of gene conversion. In one study the average length of the conversion track was estimated at $2.7 \mathrm{~kb}$ (Mikhailovsky et al., 1999), in another conversion tracks exceeding $20 \mathrm{~kb}$ were found (Kahn et al., 2000).

Although experiments using broken chromosome ends to monitor telomere elongation use an artificial system of telomere maintenance, it is assumed that the telomere elongation mechanisms identified in these experiments also work at the ends of long retrotransposon arrays. Extensions of long terminal arrays by individual transposition events or short gene conversion tracks cannot be monitored genetically or molecularly. If, however, genetic factors cause an imbalance between elongation and erosion, terminal retrotransposon arrays may grow or shrink. This can be measured cytologically by in situ hybridization on polytene 
chromosomes as changes in the terminal array length, or molecularly by quantitative PCR as changes in the genomic copy number of the telomere-specific retrotransposons.
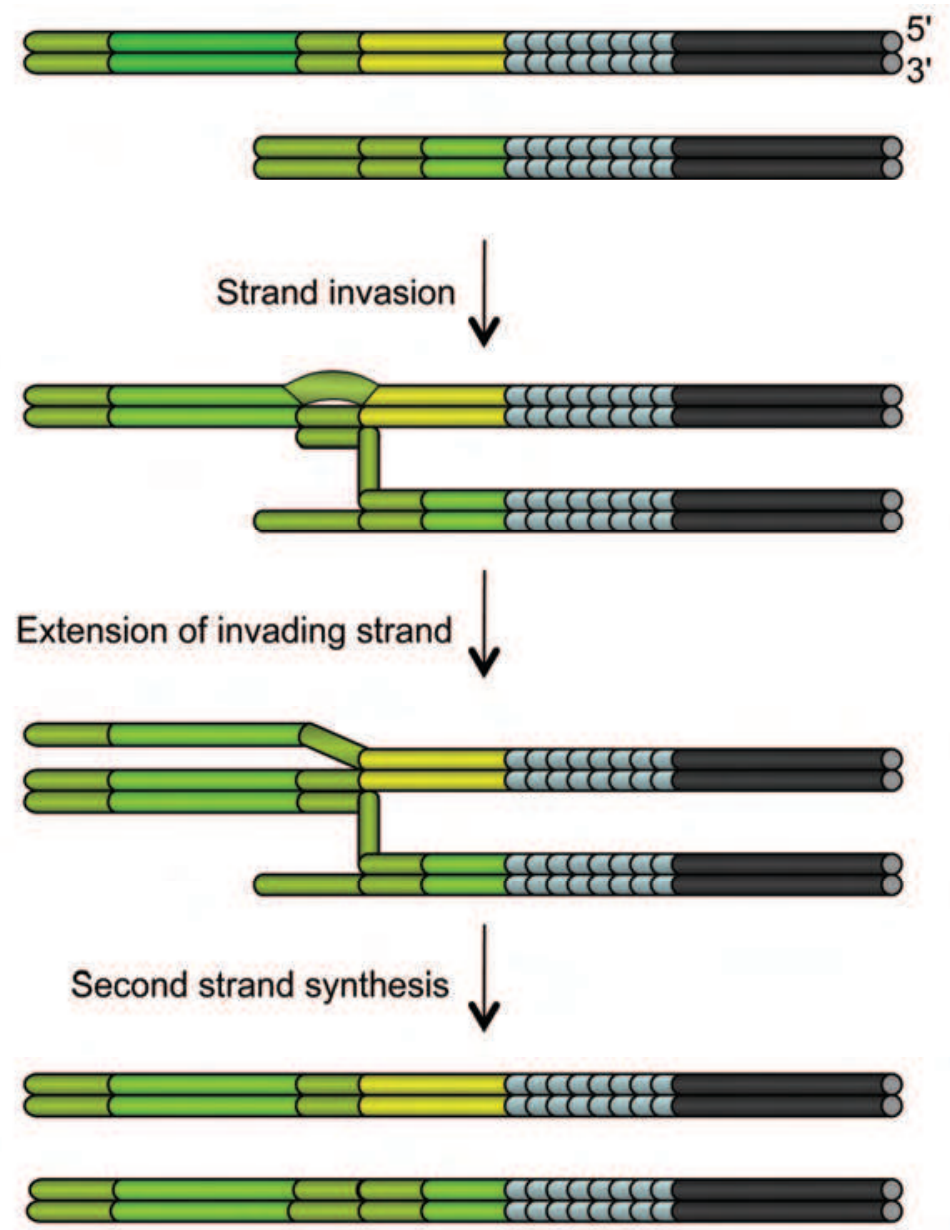

Fig. 4. Gene conversion as a mechanism for telomere elongation. The model proposes that the $3^{\prime}$ strand of a chromosome end invades another chromosome, possibly a sister or homologue. The invading strand is extended using the host sequence as a template then is used as a template in second strand synthesis. Ligation of the newly replicated fragment results in an extended chromosome.

Mutations have been identified in three genes that cause terminal transposon array length to increase. Telomere length is sensitive to HP1 concentration, as mutations in the gene encoding this protein lead to an increase in $H e T-A$ and TART transcript levels and a 100 fold increase in the frequency of new HeT-A and TART attachments (Savitsky et al., 2002). The increased rate of elongation resulted from both transposition and gene conversion, and was associated with extremely long terminal array length after several generations. As HP1 protein is enriched in 
the telomere cap, at least two possible hypotheses present themselves: (1) increased transcription increases transposition of the telomere-specific elements, and (2) disruption of the cap by decreasing one of its component proteins increases accessibility of the transposons. Our data (RCF and JMM, unpublished data), however, suggest that neither is true. Other mutations associated with increased HeT-A transcript levels are not associated with long telomeric arrays, and disruption of the cap by making heterozygous mutations in other genes encoding cap proteins does not increase telomeric array length. Two dominant mutations, $E(t c)$ and Tel (Melnikova \& Georgiev, 2002; Siriaco et al., 2002), exhibit abnormally long telomeres and are located in the same small genetic region in the middle of chromosome $3 \mathrm{R}$. In the Tel mutant the copy number of HeT-A at telomeres is increased seven-fold, while TART and TAHRE copies are increased somewhat less (Siriaco et al., 2002; Walter et al., 2007). The mechanism of action of these mutations has not been elucidated, although one study indicated that the $\mathrm{Tel}$ mutation causes telomere elongation by transposition as well as gene conversion, while $E(t c)$ causes mainly gene conversion (Proskuryakov \& Melnikova, 2008).

\subsubsection{Drosophila virilis}

The DNA sequence of individual HeT-A and TART elements in D. melanogaster differ considerably throughout their lengths, but especially in the $3^{\prime}$ UTR regions. Although it is possible to identify families of these elements, there is still some variation within each family. A comparison of telomeric retrotransposons between two sibling species of Drosophila, D. melanogaster and D. yakuba, shows substantial divergence in the HeT-A and TART UTRs but less divergence in the ORFs that encode the Gag-like polypeptides (Casacuberta \& Pardue, 2002; Danilevskaya et al., 1998b). These two elements have the most amino acid sequence conservation around the zinc knuckle motif typical of Gag proteins, and there are conserved islands scattered throughout the coding region. The overall structure of the elements, however, is well conserved. HeT-A in D. yakuba also lacks a pol ORF and has a very long 3' UTR. Although the high sequence divergence of the telomeric elements makes it difficult to find these elements in new species, it also increases the probability that the conserved features are of biological importance.

Searching for telomeric retrotransposons in more distantly related species presents a problem because of the extensive sequence divergence. Only the most conserved part of the D. melanogaster TART pol gene can cross-hybridize, even at low stringency, with D. virilis DNA. This hybridization, however, allowed the isolation of DNA fragments that provided entry into the $D$. virilis telomere arrays (Casacuberta \& Pardue, 2003a). The D. virilis TART resembles its $D$. melanogaster homolog in several respects. They are both found in tandem arrays, but not in the euchromatic arms, and they both produce an excess of antisense transcripts. The TART in D. virilis is different in that it has a relatively short 3' UTR without perfect non-terminal repeats and a pol gene (ORF2) that encodes an additional ' $\mathrm{X}$ ' domain 3 ' to the reverse transcriptase domain. A HeT-A element was found in the terminal array next to a TART from D. virilis. As with its homolog in D. melanogaster, the HeT-A element carried only a single ORF for a Gag protein and had a long 3' UTR (Casacuberta \& Pardue, 2003b). Experiments to localize GFP-tagged Gag proteins indicated that the Gag encoded by the $D$. virilis TART element requires HeT-A Gag to target the telomeres, similar to the situation found in D. melanogaster (Casacuberta et al., 2007).

There are significant differences between the telomere specific elements in D. melanogaster and $D$. virilis. HeT-A in D. virilis has its promoter in the $5^{\prime} \mathrm{UTR}$, similar to nontelomeric 
retrotransposons and thus produces transcripts that lack 5 tags. Even so, full length $H e T-A$ elements persist in the array. The $D$. virilis TART, on the other hand, has a $3^{\prime}$ promoter that generates 5' tags on its transcripts (George et al., 2010; Traverse et al., 2010). This arrangement is the reverse of that found in D. melanogaster. Unlike in D. melanogaster, the HeT-A $5^{\prime}$ UTR in D. virilis is highly conserved. This suggests a different transposition mechanism for HeT-A in these two species. Unlike the situation in D. melanogaster, in which the retrotransposons attach to the chromosome terminus, it is possible that the HeT-A element in D. virilis inserts into the 5' UTR of other elements already in the array by making a sequence-specific nick followed by target primed reverse transcription. This proposed mechanism resembles that used by canonical non-LTR retrotransposons. The ' $X$ ' domain specific to the $D$. virilis pol gene may play a role in this endonuclease activity. If it is true that $H e T-A$ elements behave differently in these two distantly related Drosophila species and that $H e T-A$ in $D$. virilis uses a mechanism similar to nontelomeric retrotransposons, then retrotransposon telomeres may have arisen near the dawn of Drosophila. HeT-A transposons in the Sophophora subgenus, which includes D. melanogaster, may have lost the endonuclease needed to nick chromosomal DNA to initiate insertion, while HeT-A transposons in the Drosophila subgenus, which includes $D$. virilis, may have retained the endonuclease but made it sequence specific. Further, if telomeric retrotransposons arose in the Drosophila genus, it follows that other Dipteran species may have other means of controlling telomere length. This is consistent with the finding of complex tandem sequence arrays at the extreme chromosome ends in Chironomus and Sciaridae species (Cohn \& Edstrom, 1992; Cohn \& Edström, 1992; Madalena et al., 2010; Nielsen \& Edstrom, 1993).

\section{Conclusion}

Although rare, telomerase has been lost several times in plants and animals. In some cases, such as Diptera, telomerase was lost in the distant past, and the descendents of this event have thrived and diversified. This raises the possibility that, once established, organisms with noncanonical mechanisms of telomere maintenance may not be at a severe selective disadvantage. How, then, do we account for the paucity of organisms lacking telomerase? One possibility is that there is a strong selective barrier to the loss of telomerase-generated DNA motifs. Binding of the shelterin protein complex necessary for the protection of chromosome ends depends on sequence-specific binding. The shelterin components TRF1 and TRF2 in particular recognize the double stranded telomeric motif, while POT1 recognizes the single stranded form (Palm \& de Lange, 2008). Thus, in most cases loss of telomerase results in loss of the telomeric motif, followed by loss of the chromosome cap, massive chromosome rearrangement and death. If, however, telomeric attachment of the cap complex in some lineages does not depend strongly on a specific DNA sequence, loss of the telomeric motif might not have the same catastrophic consequences. This might explain why insects have lost telomerase and the canonical arthropod-type telomeric sequence multiple times (Figure 1). This hypothesis assumes the existence of an effective backup mechanism that can replace the canonical telomerase system. Alternatively, it may be misleading to suggest that loss of telomerase occurred only in the small number of organisms already reported. There may be, for example, cases similar to B. mori, in which an unconventional telomere structure maintained without telomerase is camouflaged by the presence of canonical telomeric sequences. Loss of telomerase in Solanaceae, Alliaceae and 
insects may thus represent the tip of the proverbial iceberg, and it is possible that many other groups will be found with unusual telomere structures.

Recombination seems like a ready backup mechanism for telomere maintenance by transferring information from one DNA strand to another, because it is widely used by eukaryotes both during meiotic recombination and as a means of repairing DNA damage (Heyer et al., 2010). Some organisms are known to use recombination to maintain the canonical telomeric DNA sequence in the absence of telomerase. In Saccharomyces cerevisiae, for example, loss of telomerase causes gradual loss of the terminal array and ultimately cell death. A few survivors, however, appear in a recombination-dependent manner (Lundblad \& Blackburn, 1993). In mammals telomerase activity is reduced in most somatic tissues, thus limiting the growth of tumors. Most cancer cells overcome this obstacle by reactivating telomerase, but about $15 \%$ use an alternative lengthening of telomeres mechanism, which is recombination-dependent (Cesare \& Reddel, 2010). Dysfunctional telomeres may actually stimulate telomeric recombination (Brault \& Autexier, 2011). It is thus reasonable to hypothesize that a recombination-based gene conversion mechanism would be available if telomerase fails. As seen in yeast and human tumors, this pathway can maintain telomeric repeats. If the canonical motif is lost another DNA sequence, possibly related to the complex arrays of subtelomeric regions, could be maintained by the same mechanism. It is difficult to prove that organisms without telomerase use gene conversion to elongate their chromosome ends, in large part because many of these organisms lack the genetic tools to test the hypothesis. Recombination could be demonstrated in the malaria vector Anopheles gambiae because of the fortuitous transgene insertion into the telomeric array (Roth et al., 1997). In other cases it can be shown that a complex repeat array extends to, or close to, the chromosome end (Madalena et al., 2010; Nielsen \& Edstrom, 1993). In these cases gene conversion was suggested as the default mechanism. Regardless of the mechanism, it is clear that a few well established lineages of both plants and animals lack telomerase and the canonical telomeric DNA motif it produces. Elucidation of these unusual telomeres will help us to understand what it means to be a telomere.

\section{Acknowledgments}

We thank František Marec, Jan Zrzavý and Sailesh Surapureddi for valuable comments on the manuscript. The authors were supported by the Intramural Research Program of the $\mathrm{NIH}$, National Institute of Environmental Health Sciences, the MOBITAG project (Reg. No. 229518 of EU program FP7-REGPOT-2008-1) and the Institute of Entomology project Z50070508

\section{References}

Abad, J.P. \& Villasante, A. (1999). The 3' Non-Coding Region of the Drosophila melanogaster HeT-A Telomeric Retrotransposon Contains Sequences with Propensity to Form GQuadruplex DNA. FEBS Letters, Vol. 453, No. 1-2, (June 18, 1999), pp. 59-62, ISSN 0014-5793

Abad, J.P., de Pablos, B., Osoegawa, K., de Jong, P.J., Martin-Gallardo, A. \& Villasante, A. (2004a). Genomic Analysis of Drosophila melanogaster Telomeres: Full-Length Copies of HeT-A and TART Elements at Telomeres. Molecular Biology and Evolution, Vol. 21, No. 9, (September 2004), pp. 1613-1619, ISSN 0737-4038 
Abad, J.P., de Pablos, B., Osoegawa, K., de Jong, P.J., Martin-Gallardo, A. \& Villasante, A. (2004b). TAHRE, a Novel Telomeric Retrotransposon from Drosophila melanogaster, Reveals the Origin of Drosophila Telomeres. Molecular Biology and Evolution, Vol. 21, No. 9, (September 2004), pp. 1620-1624, ISSN 0737-4038

Agudo, M., Losada, A., Abad, J.P., Pimpinelli, S., Ripoll, P. \& Villasante, A. (1999). Centromeres from Telomeres? The Centromeric Region of the $Y$ Chromosome of Drosophila melanogaster Contains a Tandem Array of Telomeric HeT-A- and TARTRelated Sequences. Nucleic Acids Research, Vol. 27, No. 16, (August 1999), pp. 33183324, ISSN 0305-1048

Andreyeva, E.N., Belyaeva, E.S., Semeshin, V.F., Polkholkova, G.V. \& Zhimulev, I.F. (2005). Three Distinct Chromatin Domains in Telomere Ends of Polytene Chromosomes in Drosophila melanogaster Tel Mutants. Journal of Cell Science, Vol. 118, No. 23, (December 1, 2005), pp. 5465-5477, ISSN 1477-9137

Barnes, S.R., James, A.M. \& Jamieson, G. (1985). The Organization, Nucleotide Sequence, and Chromosomal Distribution of a Satellite DNA from Allium Cepa. Chromosoma, Vol. 92, No. 3, (June 1985), pp. 185-192, ISSN 0009-5915

Berloco, M., Fanti, L., Sheen, F., Levis, R.W. \& Pimpinelli, S. (2005). Heterochromatic Distribution of HeT-A- and TART-Like Sequences in Several Drosophila Species. Cytogenetic and Genome Research, Vol. 110, No. 1-4, pp. 124-133, ISSN 1424-8581

Biessmann, H. \& Mason, J.M. (1988). Progressive Loss of DNA Sequences from Terminal Chromosome Deficiencies in Drosophila melanogaster. EMBO Journal, Vol. 7, No. 4, (April 1998), pp. 1081-1086, ISSN 0261-4189

Biessmann, H., Carter, S.B. \& Mason, J.M. (1990a). Chromosome Ends in Drosophila without Telomeric DNA Sequences. Proceedings of the National Academy of Sciences of the United States of America, Vol. 87, No. 5, (March 1990), pp. 1758-1761, ISSN 0027-8424

Biessmann, H., Mason, J.M., Ferry, K., d'Hulst, M., Valgeirsdottir, K., Traverse, K.L. \& Pardue, M.L. (1990b). Addition of Telomere-Associated HeT DNA Sequences "Heals" Broken Chromosome Ends in Drosophila. Cell, Vol. 61, (May 18, 1990), No. 4, pp. 663-673, ISSN 0092-8674

Biessmann, H., Champion, L.E., O'Hair, M., Ikenaga, K., Kasravi, B. \& Mason, J.M. (1992a). Frequent Transpositions of Drosophila melanogaster HeT-A Transposable Elements to Receding Chromosome Ends. EMBO Journal, Vol. 11, No. 12, pp. 4459-4469, ISSN 0261-4189

Biessmann, H., Valgeirsdottir, K., Lofsky, A., Chin, C., Ginther, B., Levis, R.W. \& Pardue, M.L. (1992b). HeT-A, a Transposable Element Specifically Involved in Healing Broken Chromosome Ends in Drosophila melanogaster. Molecular and Cellular Biology, Vol. 12, No. 9, (September 1992), pp. 3910-3918, ISSN 0270-7306

Biessmann, H., Kasravi, B., Bui, T., Fujiwara, G., Champion, L.E. \& Mason, J.M. (1994). Comparison of Two Active HeT-A Retroposons of Drosophila melanogaster. Chromosoma, Vol. 103, No. 2, (April 1994), pp. 90-98, ISSN 1432-0886

Biessmann, H. \& Mason, J.M. (1997). Telomere Maintenance without Telomerase. Chromosoma, Vol. 106, No. 2, (July 1997), pp. 63-69, ISSN 1432-0886

Biessmann, H., Kobeski, F., Walter, M.F., Kasravi, A. \& Roth, C.W. (1998). DNA Organization and Length Polymorphism at the 2L Telomeric Region of Anopheles Gambiae. Insect Molecular Biology, Vol. 7, No. 1, (February 1998), pp. 83-93, ISSN 1365-2583 
Biessmann, H. \& Mason, J.M. (2003). Telomerase-Independent Mechanisms of Telomere Elongation. Cellular and Molecular Life Sciences, Vol. 60, No. 11, (November 2003), pp. 2325-2333, ISSN 1420-682X

Biessmann, H., Prasad, S., Semeshin, V.E., Andreyeva, E.N., Nguyen, Q., Walter, M.F. \& Mason, J.M. (2005). Two Distinct Domains in Drosophila melanogaster Telomeres. Genetics, Vol. 171, No. 4, (December 2005), pp. 1767-1777, ISSN 0016-6731

Blackburn, E.H. \& Gall, J.G. (1978). A Tandemly Repeated Sequence at the Termini of the Extrachromosomal Ribosomal RNA Genes in Tetrahymena. Journal of Molecular Biology, Vol. 120, No. 1, (March 25, 1978), pp. 33-53, ISSN 0022-2836

Boivin, A., Gally, C., Netter, S., Anxolabehere, D. \& Ronsseray, S. (2003). Telomeric Associated Sequences of Drosophila Recruit Polycomb-Group Proteins in Vivo and Can Induce Pairing-Sensitive Repression. Genetics, Vol. 164, No. 1, (May 2003), pp. 195-208, ISSN 0016-6731

Brault, M.E. \& Autexier, C. (2011). Telomeric Recombination Induced by Dysfunctional Telomeres. Molecular Biology of the Cell, Vol. 22, No. 2, (January 2011), pp. 179-188, ISSN 1059-1524

Capkova Frydrychova, R., Biessmann, H., Konev, A.Y., Golubovsky, M.D., Johnson, J., Archer, T.K. \& Mason, J.M. (2007). Transcriptional Activity of the Telomeric Retrotransposon HeT-A in Drosophila melanogaster Is Stimulated as a Consequence of Subterminal Deficiencies at Homologous and Nonhomologous Telomeres. Molecular and Cellular Biology, Vol. 27, No. 13, (July 2007), pp. 4991-5001, ISSN 02707306

Capkova Frydrychova, R., Biessmann, H. \& Mason, J.M. (2008). Regulation of Telomere Length in Drosophila. Cytogenetic and Genome Research, Vol. 122, (February 2009), pp. 356-364, ISSN 1424-8581

Casacuberta, E. \& Pardue, M.L. (2002). Coevolution of the Telomeric Retrotransposons across Drosophila Species. Genetics, Vol. 161, No. 3, (July 2002), pp. 1113-1124, ISSN 0016-6731

Casacuberta, E. \& Pardue, M.L. (2003a). Transposon Telomeres Are Widely Distributed in the Drosophila Genus: TART Elements in the Virilis Group. Proceedings of the National Academy of Sciences of the United States of America, Vol. 100, No. 6, (March 18, 2003), pp. 3363-3368, ISSN 0027-8424

Casacuberta, E. \& Pardue, M.L. (2003b). HeT-A Elements in Drosophila virilis: Retrotransposon Telomeres Are Conserved across the Drosophila Genus. Proceedings of the National Academy of Sciences of the United States of America, Vol. 100, No. 24, (November 25, 2003), pp. 14091-14096, ISSN 0027-8424

Casacuberta, E. \& Pardue, M.L. (2005). HeT-A and TART, Two Drosophila Retrotransposons with a Bona Fide Role in Chromosome Structure for More Than 60 Million Years. Cytogenetic and Genome Research, Vol. 110, No. 1-4, pp. 152-159, ISSN 1424-8581

Casacuberta, E., Marin, F.A. \& Pardue, M.L. (2007). Intracellular Targeting of Telomeric Retrotransposon Gag Proteins of Distantly Related Drosophila Species. Proceedings of the National Academy of Sciences of the United States of America, Vol. 104, No. 20, (May 15, 2007), pp. 8391-8396, ISSN 0027-8424

Cenci, G., Siriaco, G., Raffa, G.D., Kellum, R. \& Gatti, M. (2003). The Drosophila HOAP Protein Is Required for Telomere Capping. Nature Cell Biology, Vol. 5, No. 1, (January 2003), pp. 82-84, ISSN 1465-7392 
Cenci, G., Ciapponi, L. \& Gatti, M. (2005). The Mechanism of Telomere Protection: A Comparison between Drosophila and Humans. Chromosoma, Vol. 114, No. 3, (August 2003), pp. 135-145, ISSN 1432-0886

Cesare, A.J. \& Reddel, R.R. (2010). Alternative Lengthening of Telomeres: Models, Mechanisms and Implications. Nature Reviews in Genetics, Vol. 11, No. 5, (May 2010), pp. 319-330, ISSN 1471-0056

Ciapponi, L. \& Cenci, G. (2008). Telomere Capping and Cellular Checkpoints: Clues from Fruit Flies. Cytogenetic and Genome Research, Vol. 122, No. 3-4, (February 2009), pp. 365-373, ISSN 1424-859X

Cohn, M. \& Edstrom, J.E. (1992). Telomere-Associated Repeats in Chironomus Form Discrete Subfamilies Generated by Gene Conversion. Journal of Molecular Evolution, Vol. 35, No. 2, (August 1992), pp. 114-122, ISSN 0737-4038

Cohn, M. \& Edström, J.E. (1992). Chromosome Ends in Chironomus Pallidivittatus Contain Different Subfamilies of Telomere-Associated Repeats. Chromosoma, Vol. 101, No. 10, (October 1992), pp. 634-640, ISSN 1432-0886

Cryderman, D.E., Morris, E.J., Biessmann, H., Elgin, S.C.R. \& Wallrath, L.L. (1999). Silencing at Drosophila Telomeres: Nuclear Organization and Chromatin Structure Play Critical Roles. EMBO Journal, Vol. 18, No. 13, (July 1, 1999), pp. 3724-3735, ISSN 0261-4189

Danilevskaya, O.N., Arkhipova, I.R., Traverse, K.L. \& Pardue, M.L. (1997). Promoting in Tandem: The Promoter for Telomere Transposon HeT-A and Implications for the Evolution of Retroviral LTRs. Cell, Vol. 88, No. 5, (March 7, 1997), pp. 647-655, ISSN 0092-8674

Danilevskaya, O.N., Lowenhaupt, K. \& Pardue, M.L. (1998a). Conserved Subfamilies of the Drosophila HeT-A Telomere- Specific Retrotransposon. Genetics, Vol. 148, No. 1, (January 1998), pp. 233-242, ISSN 0016-6731

Danilevskaya, O.N., Tan, C., Wong, J., Alibhai, M. \& Pardue, M.L. (1998b). Unusual Features of the Drosophila melanogaster Telomere Transposable Element HeT-A Are Conserved in Drosophila yakuba Telomere Elements. Proceedings of the National Academy of Sciences of the United States of America, Vol. 95, No. 7, (March 31, 1998), pp. 3770-3775, ISSN 0027-8424

Danilevskaya, O.N., Traverse, K.L., Hogan, N.C., Debaryshe, P.G. \& Pardue, M.L. (1999). The Two Drosophila Telomeric Transposable Elements Have Very Different Patterns of Transcription. Molecular and Cellular Biology, Vol. 19, No. 1, (January 1999), pp. 873-881, ISSN 0270-7306

Fajkus, J., Kovarik, A., Kralovics, R. \& Bezdek, M. (1995). Organization of Telomeric and Subtelomeric Chromatin in the Higher Plant Nicotiana Tabacum. Molecular and General Genetics, Vol. 247, No. 5, (September 1995), pp. 633-638, ISSN 1432-1874

Fajkus, J., Sykorova, E. \& Leitch, A.R. (2005). Telomeres in Evolution and Evolution of Telomeres. Chromosome Research, Vol. 13, No. 5, (July 2005), pp. 469-479, ISSN 09673849

Fanti, L., Giovinazzo, G., Berloco, M. \& Pimpinelli, S. (1998). The Heterochromatin Protein 1 Prevents Telomere Fusions in Drosophila. Molecular Cell, Vol. 2, No. 5, (November 1998), pp. 527-538, ISSN 1097-2765 
Frydrychova, R., Grossmann, P., Trubac, P., Vitkova, M. \& Marec, F.E. (2004). Phylogenetic Distribution of TTAGG Telomeric Repeats in Insects. Genome, Vol. 47, No. 1, (February 1, 2004), pp. 163-178, ISSN 1480-3321

Fuchs, J., Brandes, A. \& Schubert, I. (1995). Telomere Sequence Localization and Karyotype Evolution in Higher Plants. Plant Systematics and Evolution, Vol. 196, No. 3-4, (September 1995), pp. 227-241, ISSN 0378-2697

Fuchs, J. \& Schubert, I. (1996). Arabidopsis-Type Telomere Sequences on Chromosome Termini of Selaginella Martensii Spring (Pteridophyta). Biologisches Zentralblatt, Vol. 115, No. 4, pp. $260-265$

Fujiwara, H., Osanai, M., Matsumoto, T. \& Kojima, K.K. (2005). Telomere-Specific Non-LTR Retrotransposons and Telomere Maintenance in the Silkworm, Bombyx mori. Chromosome Research, Vol. 13, No. 5, (July 2005), pp. 455-467, ISSN 0967-3849

Fuller, A.M., Cook, E.G., Kelley, K.J. \& Pardue, M.L. (2010). Gag Proteins of Drosophila Telomeric Retrotransposons: Collaborative Targeting to Chromosome Ends. Genetics, Vol. 184, No. 3, (March 2010), pp. 629-U637, ISSN 0016-6731

Gao, G.J., Walser, J.C., Beaucher, M.L., Morciano, P., Wesolowska, N., Chen, J. \& Rong, Y.S. (2010). Hiphop Interacts with HOAP and HP1 to Protect Drosophila Telomeres in a Sequence-Independent Manner. EMBO Journal, Vol. 29, No. 4, (February 2010), pp. 819-829, ISSN 0261-4189

George, J.A., Traverse, K.L., DeBaryshe, P.G., Kelley, K.J. \& Pardue, M.L. (2010). Evolution of Diverse Mechanisms for Protecting Chromosome Ends by Drosophila TART Telomere Retrotransposons. Proceedings of the National Academy of Sciences of the United States of America, Vol. 107, No. 49, (December 2010), pp. 21052-21057, ISSN 0027-8424

Golubovsky, M.D., Konev, A.Y., Walter, M.F., Biessmann, H. \& Mason, J.M. (2001). Terminal Retrotransposons Activate a Subtelomeric white Transgene at the 2L Telomere in Drosophila. Genetics, Vol. 158, No. 3, (July 2001), pp. 1111-1123, ISSN 0016-6731

Greider, C.W. (1996). Telomere Length Regulation. Annual Review of Biochemistry, Vol. 65, pp. 337-365, ISSN 0066-4154

Griffith, J.D., Comeau, L., Rosenfield, S., Stansel, R.M., Bianchi, A., Moss, H. \& de Lange, T. (1999). Mammalian Telomeres End in a Large Duplex Loop. Cell, Vol. 97, No. 4, (May 14, 1999), pp. 503-514, ISSN 0092-8674

Heyer, W.D., Ehmsen, K.T. \& Liu, J. (2010). Regulation of Homologous Recombination in Eukaryotes. Annual Review of Genetics, Vol. 44, pp. 113-139, ISSN 1545-2948

Kahn, T., Savitsky, M. \& Georgiev, P. (2000). Attachment of HeT-A Sequences to Chromosomal Termini in Drosophila melanogaster May Occur by Different Mechanisms. Molecular and Cellular Biology, Vol. 20, No. 20, (October 2000), pp. 7634-7642, ISSN 0270-7306

Karpen, G.H. \& Spradling, A.C. (1992). Analysis of Subtelomeric Heterochromatin in the Drosophila Minichromosome Dp1187 by Single-P Element Insertional Mutagenesis. Genetics, Vol. 132, No. 3, (November 1992), pp. 737-753, ISSN 0016-6731

Klobutcher, L.A., Swanton, M.T., Donini, P. \& Prescott, D.M. (1981). All Gene-Sized DNA Molecules in Four Species of Hypotrichs Have the Same Terminal Sequence and an Unusual 3' Terminus. Proceedings of the National Academy of Sciences of the United States of America, Vol. 78, No. 5, (May 15, 1981), pp. 3015-3019, ISSN 0027-8424 
Kubo, Y., Okazaki, S., Anzai, T. \& Fujiwara, H. (2001). Structural and Phylogenetic Analysis of TRAS, Telomeric Repeat-Specific Non-LTR Retrotransposon Families in Lepidopteran Insects. Molecular Biology and Evolution, Vol. 18, No. 5, (May 2001), pp. 848-857, ISSN 0737-4038

Kurenova, E., Champion, L., Biessmann, H. \& Mason, J.M. (1998). Directional Gene Silencing Induced by a Complex Subtelomeric Satellite from Drosophila. Chromosoma, Vol. 107, No. 5, (November 1998), pp. 311-320, ISSN 1432-0886

Levis, R.W. (1989). Viable Deletions of a Telomere from a Drosophila Chromosome. Cell, Vol. 58, No. 4, (August 25, 1989), pp. 791-801, ISSN 0092-8674

Lundblad, V. \& Blackburn, E.H. (1993). An Alternative Pathway for Yeast Telomere Maintenance Rescues Est1- Senescence. Cell, Vol. 73, No. 2, (April 23, 1993), pp. 347360, ISSN 0092-8674

Madalena, C.R.G., Amabis, J.M. \& Gorab, E. (2010). Unusually Short Tandem Repeats Appear to Reach Chromosome Ends of Rhynchosciara americana (Diptera: Sciaridae). Chromosoma, Vol. 119, No. 6, (December 2010), pp. 613-623, ISSN 0009-5915

Mason, J.M. \& Biessmann, H. (1995). The Unusual Telomeres of Drosophila. Trends in Genetics, Vol. 11, No. 2, (February 1995) pp. 58-62, ISSN 0168-9525

Mason, J.M., Konev, A.Y. \& Biessmann, H. (2003a). Telomeric Position Effect in Drosophila melanogaster Reflects a Telomere Length Control Mechanism. Genetica, Vol. 117, No. 2, (March 2003), pp. 319-325, ISSN 0016-6707

Mason, J.M., Konev, A.Y., Golubovsky, M.D. \& Biessmann, H. (2003b). Cis- and Trans-Acting Influences on Telomeric Position Effect in Drosophila melanogaster Detected with a Subterminal Transgene. Genetics, Vol. 163, No. 3, (March 2003), pp. 917-930, ISSN 0016-6731

Matsumoto, T., Fukui, K., Niwa, O., Sugawara, N., Szostak, J.W. \& Yanagida, M. (1987). Identification of Healed Terminal DNA Fragments in Linear Minichromosomes of Schizosaccharomyces pombe. Molecular and Cellular Biology, Vol. 7, No. 12, (December 1987), pp. 4424-4430, ISSN 0270-7306

Maxwell, P.H., Belote, J.M. \& Levis, R.W. (2006). Identification of Multiple Transcription Initiation, Polyadenylation, and Splice Sites in the Drosophila melanogaster TART Family of Telomeric Retrotransposons. Nucleic Acids Research, Vol. 34, No. 19, (November 2006), pp. 5498-5507, ISSN 0305-1048

McClintock, B. (1941). The Stability of Broken Ends of Chromosomes in Zea Mays. Genetics, Vol. 26, No. 2, (March 1941), pp. 234-282, ISSN 0016-6731

Melnikova, L. \& Georgiev, P. (2002). Enhancer of Terminal Gene Conversion, a New Mutation in Drosophila melanogaster That Induces Telomere Elongation by Gene Conversion. Genetics, Vol. 162, No. 3, (November 2002), pp. 1301-1312, ISSN 00166731

Melnikova, L. \& Georgiev, P. (2005). Drosophila Telomeres: The Non-Telomerase Alternative. Chromosome Research, Vol. 13, No. 5, (July 2005), pp. 431-441, ISSN 0967-3849

Meyne, J., Ratliff, R.L. \& Moyzis, R.K. (1989). Conservation of the Human Telomere Sequence (TTAGGG)n among Vertebrates. Proceedings of the National Academy of Sciences of the United States of America, Vol. 86, No. 18, (September 15, 1989), pp. 7049-7053, ISSN 0027-8424 
Mikhailovsky, S., Belenkaya, T. \& Georgiev, P. (1999). Broken Chromosomal Ends Can Be Elongated by Conversion in Drosophila melanogaster. Chromosoma, Vol. 108, No. 2, (May 1999), pp. 114-120, ISSN 0009-5915

Nielsen, L. \& Edstrom, J.E. (1993). Complex Telomere-Associated Repeat Units in Members of the Genus Chironomus Evolve from Sequences Similar to Simple Telomeric Repeats. Molecular and Cellular Biology, Vol. 13, No. 3, (March 1993), pp. 1583-1589, ISSN 0270-7306

Oka, Y., Shiota, S., Nakai, S., Nishida, Y. \& Okubo, S. (1980). Inverted Terminal Repeat Sequence in the Macronuclear DNA of Stylonychia pustulata. Gene, Vol. 10, (September 1980), pp. 301-306, ISSN 0378-1119

Okazaki, S., Tsuchida, K., Maekawa, H., Ishikawa, H. \& Fujiwara, H. (1993). Identification of a Pentanucleotide Telomeric Sequence, (TTAGG)n, in the Silkworm Bombyx mori and in Other Insects. Molecular and Cellular Biology, Vol. 13, No. 3, (March 1993), pp. 1424-1432, ISSN 0270-7306

Okazaki, S., Ishikawa, H. \& Fujiwara, H. (1995). Structural Analysis of TRAS1, a Novel Family of Telomeric Repeat-Associated Retrotransposons in the Silkworm, Bombyx mori. Molecular and Cellular Biology, Vol. 15, No. 8, (August 1995), pp. 4545-4552, ISSN 0270-7306

Olovnikov, A.M. (1973). A Theory of Marginotomy. Journal of Theoretical Biology, Vol. 41, No. 1 (September 14, 1973) ,pp. 181-190, ISSN 0022-5193

Palm, W. \& de Lange, T. (2008). How Shelterin Protects Mammalian Telomeres. Annual Review of Genetics, Vol. 42, pp. 301-334, ISSN 0066-4197

Pardue, M.L. \& DeBaryshe, P.G. (2003). Retrotransposons Provide an Evolutionarily Robust Non-Telomerase Mechanism to Maintain Telomeres. Annual Review of Genetics, Vol. 37, pp. 485-511, ISSN 0066-4197

Pardue, M.L. \& DeBaryshe, P.G. (2008). Drosophila Telomeres - a Variation on the Telomerase Theme. Fly, Vol. 2, No. 3, (May 2008), pp. 101-110, ISSN 1933-6934

Pearce, S.R., Pich, U., Harrison, G., Flavell, A.J., Heslop-Harrison, J.S.P., Schubert, I. \& Kumar, A. (1996). The Ty1-Copia Group Retrotransposons of Allium Cepa Are Distributed Throughout the Chromosomes but Are Enriched in the Terminal Heterochromatin. Chromosome Research., Vol. 4, No. 5, (November 1996), pp. 357364, ISSN 0967-3849

Peska, V., Sykorova, E. \& Fajkus, J. (2008). Two Faces of Solanaceae Telomeres: A Comparison between Nicotiana and Cestrum Telomeres and Telomere-Binding Proteins. Cytogenetics and Genome Research, Vol. 122, No. 3-4, (December 2008), pp. 380-387, ISSN 1424-8581

Pich, U., Fuchs, J. \& Schubert, I. (1996). How Do Alliaceae Stabilize Their Chromosome Ends in the Absence of TTTAGGG Sequences? Chromosome Research., Vol. 4, No. 3, (April 1996), pp. 207-213, ISSN 0967-3849

Pich, U. \& Schubert, I. (1998). Terminal Heterochromatin and Alternative Telomeric Sequences in Allium cepa. Chromosome Research, Vol. 6, No. 4, (June 1998), pp. 315321, ISSN 0967-3849

Proskuryakov, K.A. \& Melnikova, L.S. (2008). Functional Separation of Genetic Factors Telomere Elongation (Tel) and Enhancer of Terminal Gene Conversion $(E(t c))$ Involved in Telomere Elongation in Drosophila melanogaster. Doklady Biochemistry and Biophysics, Vol. 421, No. 1, (August 2008), pp. 199-203, ISSN 1607-6729 
Pryde, F.E., Gorham, H.C. \& Louis, E.J. (1997). Chromosome Ends: All the Same under Their Caps. Current Opinion in Genetics and Development, Vol. 7, No. 6 (December 1997), pp. 822-828, ISSN 0959-437X

Raffa, G.D., Siriaco, G., Cugusi, S., Ciapponi, L., Cenci, G., Wojcik, E. \& Gatti, M. (2009). The Drosophila Modigliani (Moi) Gene Encodes a HOAP-Interacting Protein Required for Telomere Protection. Proceedings of the National Academy of Sciences of the United States of America, Vol. 106, No. 7, (February 17, 2009), pp. 2271-2276, ISSN 0027-8424

Raffa, G.D., Raimondo, D., Sorino, C., Cugusi, S., Cenci, G., Cacchione, S., Gatti, M. \& Ciapponi, L. (2010). Verrocchio, a Drosophila Ob Fold-Containing Protein, Is a Component of the Terminin Telomere-Capping Complex. Genes and Development, Vol. 24, No. 15, (August 2010), pp. 1596-1601, ISSN 0890-9369

Rashkova, S., Karam, S.E., Kellum, R. \& Pardue, M.L. (2002a). Gag Proteins of the Two Drosophila Telomeric Retrotransposons Are Targeted to Chromosome Ends. Journal of Cell Biology, Vol. 159, No. 3, (November 11, 2002), pp. 397-402, ISSN 0021-9525

Rashkova, S., Karam, S.E. \& Pardue, M.L. (2002b). Element-Specific Localization of Drosophila Retrotransposon Gag Proteins Occurs in Both Nucleus and Cytoplasm. Proceedings of the National Academy of Sciences of the United States of America, Vol. 99, No. 6, (March 19, 2002), pp. 3621-3626, ISSN 0027-8424

Richards, E.J. \& Ausubel, F.M. (1988). Isolation of a Higher Eukaryotic Telomere from Arabidopsis thaliana. Cell, Vol. 53, No. 1, (April 8, 1988), pp. 127-136, ISSN 0092-8674

Roseman, R.R., Johnson, E.A., Rodesch, C.K., Bjerke, M., Nagoshi, R.N. \& Geyer, P.K. (1995). A $P$ Element Containing Suppressor of Hairy-Wing Binding Regions Has Novel Properties for Mutagenesis in Drosophila melanogaster. Genetics, Vol. 141, No. 3, (November 1995), pp. 1061-1074, ISSN 0016-6731

Roth, C.W., Kobeski, F., Walter, M.F. \& Biessmann, H. (1997). Chromosome End Elongation by Recombination in the Mosquito Anopheles gambiae. Molecular and Cellular Biology, Vol. 17, No. 9, (September 1997), pp. 5176-5183, ISSN 0270-7306

Russo, C.A., Takezaki, N. \& Nei, M. (1995). Molecular Phylogeny and Divergence Times of Drosophilid Species. Molecular Biology and Evolution, Vol. 12, No. 3, (May 1995), pp. 391-404, ISSN 0737-4038

Savitsky, M., Kravchuk, O., Melnikova, L. \& Georgiev, P. (2002). Heterochromatin Protein 1 Is Involved in Control of Telomere Elongation in Drosophila melanogaster. Molecular and Cellular Biology, Vol. 22, No. 9, (May 2002), pp. 3204-3218, ISSN 0270-7306

Savitsky, M., Kwon, D., Georgiev, P., Kalmykova, A. \& Gvozdev, V. (2006). Telomere Elongation Is under the Control of the RNAi-Based Mechanism in the Drosophila Germline. Genes and Development, Vol. 20, No. 3, (February 2006), pp. 345-354, ISSN 0890-9369

Schmid, K.J. \& Tautz, D. (1997). A Screen for Fast Evolving Genes from Drosophila. Proceedings of the National Academy of Sciences of the United States of America, Vol. 94, No. 18, (September 2, 1997), pp. 9746-9750, ISSN 0027-8424

Shampay, J., Szostak, J.W. \& Blackburn, E.H. (1984). DNA Sequences of Telomeres Maintained in Yeast. Nature, Vol. 310, No. 5973, (July 12, 1984), pp. 154-157, ISSN

Sheen, F.M. \& Levis, R.W. (1994). Transposition of the Line-Like Retrotransposon TART to Drosophila Chromosome Termini. Proceedings of the National Academy of Sciences of the United States of America, Vol. 91, No. 26, (December 20, 1994), pp. 12510-12514, ISSN 0027-8424 
Shpiz, S., Kwon, D., Uneva, A., Kim, M., Klenov, M., Rozovsky, Y., Georgiev, P., Savitsky, M. \& Kalmykova, A. (2007). Characterization of Drosophila Telomeric Retroelement TAHRE: Transcription, Transpositions, and RNAi-Based Regulation of Expression. Molecular Biology and Evolution, Vol. 24, No. 11, (November 2007), pp. 2535-2545, ISSN 0737-4038

Shpiz, S., Kwon, D., Rozovsky, Y. \& Kalmykova, A. (2009). rasiRNA Pathway Controls Antisense Expression of Drosophila Telomeric Retrotransposons in the Nucleus. Nucleic Acids Research, Vol. 37, No. 1, (January 2009), pp. 268-278, ISSN 0305-1048

Siriaco, G.M., Cenci, G., Haoudi, A., Champion, L.E., Zhou, C., Gatti, M. \& Mason, J.M. (2002). Telomere Elongation (Tel), a New Mutation in Drosophila melanogaster That Produces Long Telomeres. Genetics, Vol. 160, No. 1, (January 2002), pp. 235-245, ISSN 0016-6731

Sykorova, E., Lim, K.Y., Kunicka, Z., Chase, M.W., Bennett, M.D., Fajkus, J. \& Leitch, A.R. (2003). Telomere Variability in the Monocotyledonous Plant Order Asparagales. Proceedings. Biological Sciences/The Royal Society, Vol. 270, No. 1527, (September 2003), pp. 1893-1904, ISSN 0962-8452

Tatsuke, T., Sakashita, K., Masaki, Y., Lee, J.M., Kawaguchi, Y. \& Kusakabe, T. (2009). The Telomere-Specific Non-LTR Retrotransposons SART1 and TRAS1 Are Suppressed by Piwi Subfamily Proteins in the Silkworm, Bombyx mori. Cellular \& Molecular Biology Letters, Vol. 15, No. 1, (March 2009), pp. 118-133, ISSN 1425-8153

Traut, W., Szczepanowski, M., Vitkova, M., Opitz, C., Marec, F. \& Zrzavy, J. (2007). The Telomere Repeat Motif of Basal Metazoa. Chromosome Research, Vol. 15, No. 3, (April 2007), pp. 371-382, ISSN 0967-3849

Traverse, K.L., George, J.A., DeBaryshe, P.G. \& Pardue, M.L. (2010). Evolution of SpeciesSpecific Promoter-Associated Mechanisms for Protecting Chromosome Ends by Drosophila HeT-A Telomeric Transposons. Proceedings of the National Academy of Sciences of the United States of America, Vol. 107, No. 11, (March 16, 2010), pp. 50645069, ISSN 0027-8424

Villasante, A., Abad, J.P., Planello, R., Mendez-Lago, M., Celniker, S.E. \& de Pablos, B. (2007). Drosophila Telomeric Retrotransposons Derived from an Ancestral Element That Was Recruited to Replace Telomerase. Genome Research, Vol. 17, No. 12, (December 2007), pp. 1909-1918, ISSN 1088-9051

Vitkova, M., Kral, J., Traut, W., Zrzavy, J. \& Marec, F. (2005). The Evolutionary Origin of Insect Telomeric Repeats, (TTAGG)(n). Chromosome Research, Vol. 13, No. 2, (January 2005), pp. 145-156, ISSN 0967-3849

Walter, M.F., Jang, C., Kasravi, B., Donath, J., Mechler, B.M., Mason, J.M. \& Biessmann, H. (1995). DNA Organization and Polymorphism of a Wild-Type Drosophila Telomere Region. Chromosoma, Vol. 104, No. 4, (December 1995), pp. 229-241, ISSN 1432-0886

Walter, M.F., Biessmann, M.R., Benitez, C., Török, T., Mason, J.M. \& Biessmann, H. (2007). Effects of Telomere Length in Drosophila melanogaster on Life Span, Fecundity, and Fertility. Chromosoma, Vol. 116, No. 1, (February 2007), pp. 41-51, ISSN 1432-0886

Wang, S.S. \& Zakian, V.A. (1990). Sequencing of Saccharomyces Telomeres Cloned Using T4 DNA Polymerase Reveals Two Domains. Molecular and Cellular Biology, Vol. 10, No. 8, (August 1990), pp. 4415-4419, ISSN 0270-7306

Watson, J.D. (1972). Origin of Concatameric T7 DNA. Nature New Biology, Vol. 239, No. 94, (October 18, 1972), pp. 197-201, ISSN : 0028-0836 
Watson, J.M. \& Riha, K. (2010). Comparative Biology of Telomeres: Where Plants Stand. FEBS Letters, Vol. 584, No. 17, (September 2010), pp. 3752-3759, ISSN 0014-5793

Weiss, H. \& Scherthan, H. (2002). Aloe Spp. - Plants with Vertebrate-Like Telomeric Sequences. Chromosome Research, Vol. 10, No. 2, (March 2002), pp. 155-164, ISSN 0967-3849

Wellinger, R.J., Ethier, K., Labrecque, P. \& Zakian, V.A. (1996). Evidence for a New Step in Telomere Maintenance. Cell, Vol. 85, No. 3, (May 3, 1996), pp. 423-433, ISSN 00928674

Zellinger, B. \& Riha, K. (2007). Composition of Plant Telomeres. Biochimica et Biophysica ActaGene Structure and Expression, Vol. 1769, No. 5-6, (May 2007), pp. 399-409, ISSN 0167-4781 


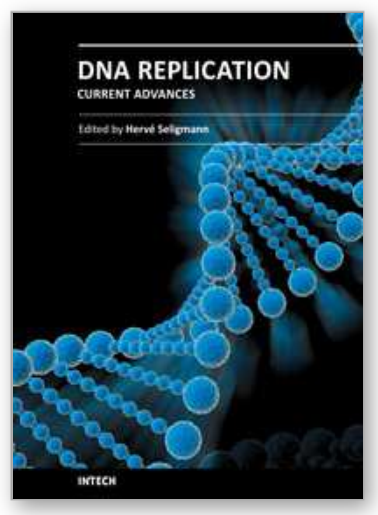

\section{DNA Replication-Current Advances}

Edited by Dr Herve Seligmann

ISBN 978-953-307-593-8

Hard cover, 694 pages

Publisher InTech

Published online 01, August, 2011

Published in print edition August, 2011

The study of DNA advanced human knowledge in a way comparable to the major theories in physics, surpassed only by discoveries such as fire or the number zero. However, it also created conceptual shortcuts, beliefs and misunderstandings that obscure the natural phenomena, hindering its better understanding. The deep conviction that no human knowledge is perfect, but only perfectible, should function as a fair safeguard against scientific dogmatism and enable open discussion. With this aim, this book will offer to its readers 30 chapters on current trends in the field of DNA replication. As several contributions in this book show, the study of DNA will continue for a while to be a leading front of scientific activities.

\section{How to reference}

In order to correctly reference this scholarly work, feel free to copy and paste the following:

James M. Mason, Hemakumar M. Reddy and Radmila Capkova Frydrychova (2011). Telomere Maintenance in Organisms without Telomerase, DNA Replication-Current Advances, Dr Herve Seligmann (Ed.), ISBN: 978953-307-593-8, InTech, Available from: http://www.intechopen.com/books/dna-replication-currentadvances/telomere-maintenance-in-organisms-without-telomerase

\section{INTECH}

open science | open minds

\section{InTech Europe}

University Campus STeP Ri

Slavka Krautzeka 83/A

51000 Rijeka, Croatia

Phone: +385 (51) 770447

Fax: +385 (51) 686166

www.intechopen.com

\section{InTech China}

Unit 405, Office Block, Hotel Equatorial Shanghai

No.65, Yan An Road (West), Shanghai, 200040, China

中国上海市延安西路65号上海国际贵都大饭店办公楼405单元

Phone: +86-21-62489820

Fax: +86-21-62489821 
(C) 2011 The Author(s). Licensee IntechOpen. This chapter is distributed under the terms of the Creative Commons Attribution-NonCommercialShareAlike-3.0 License, which permits use, distribution and reproduction for non-commercial purposes, provided the original is properly cited and derivative works building on this content are distributed under the same license. 